\title{
ANÁLISE DO PROCESSO DE LICENCIAMENTO AMBIENTAL NO ESTADO DO RIO DE JANEIRO
}

\section{ANALYSIS ON THE ENVIRONMENTAL PERMITTING PROCESS IN RIO DE JANEIRO}

\author{
Breno Maurício Pantoja da Silva \\ Universidade Federal do Rio de Janeiro \\ E-mail: brenomamauricio@poli.ufrj.br \\ Paulina Maria Porto Silva Cavalcanti \\ Instituto Estadual do Ambiente do Estado do Rio de Janeiro \\ E-mail: paulina.porto@gmail.com \\ Manoel Gonçalves Rodrigues \\ Observatório Urbano/UERJ/UN-Habitat \\ E-mail: manoel.rodrigues@terra.com.br \\ Josimar Ribeiro de Almeida \\ Observatório Urbano/UERJ/UN-Habitat \\ E-mail: almeida@poli.ufrj.br
}

\section{RESUMO}

O licenciamento ambiental é um conjunto de atos coordenados com a finalidade do poder público declarar a viabilidade de implantação de empreendimentos. No Estado do Rio de Janeiro, o Instituto Estadual do Ambiente (Inea) é responsável por conduzir os processos de licenciamento de atividades ou empreendimentos utilizadores de recursos ambientais, efetiva ou potencialmente poluidores, capazes de causar degradação ao meio ambiente. Assim, este trabalho objetivou identificar os entraves enfrentados para obtenção de licenças ambientais no órgão licenciador do Rio de Janeiro, por meio da utilização de métodos e técnicas de análise documental de amostragem não probabilística, entre os anos 2012 e 2013. A pesquisa identificou a existência de uma série de fatores que influenciam negativamente no processo de licenciamento acarretando na chamada ineficiência da gestão ambiental. Os empreendedores falham ao apresentar rotineiramente projetos inconsistentes e estudos ambientais frágeis, obrigando-os a complementá-los no curso do processo de licenciamento. De outra forma, o órgão licenciador também enfrenta uma série desafios de modernização dos processos da AIA que contribuem no prolongamento do tempo de emissão da licença ambiental requerida pelo empreendedor. Por fim, o estudo indica a necessidade de melhoria contínua do processo, sugerindo o desenvolvimento de parcerias e reformulação de procedimentos operacionais e normas administrativas.

Palavras-chave: Processo; Licenciamento Ambiental; Entrave; Avaliação de Impacto Ambiental. 


\begin{abstract}
The environmental permitting is a set of coordinated acts that aims declaring the environmental feasibility of a venture implementation. In Rio de Janeiro, the Instituto Estadual do Ambiente (Inea) is the responsible for conducting the environmental permitting process for effective or potentially polluting activities/ventures, that use environmental resources and that are capable of causing the environmental degradation. Therefore, this work focuses on the identification of obstacles encountered in the issuance of environmental permits inside Rio de Janeiro"s licensing agency, though the use of methods and techniques for documentary analysis using non -probability sampling, between 2012 and 2013. The research identified a series of factors that negatively influence the licensing process resulting in environmental management inefficiency. Entrepreneurs fail when submitting inconsistent projects and fragile environmental studies, requiring complements during the licensing process. Otherwise, the licensing agency also faces a series of challenges on the modernization of EIA processes that contribute to prolong the issuance time of environmental permits required by entrepreneurs. At last, the study indicates the need for continuous process improvements, suggesting the $d$ evelopment of partnerships and reformulation of operational procedures and administrative laws.
\end{abstract}

Keywords: Process; Environmental Permitting; Obstacle; Environmental Impact Assessment.

\title{
INTRODUÇÃO
}

Com base nas diretrizes da Polícia Nacional de Meio Ambiente (PNMA), foi criado, em 2007, o Instituto Estadual do Ambiente (Inea), órgão ambiental do Estado do Rio de janeiro (ERJ), responsável por conduzir, no âmbito estadual, os processos de licenciamento de atividades ou empreendimentos utilizadores de recursos ambientais, efetiva ou potencialmente poluidores capazes de causar degradação ao meio ambiente.

O Sistema de Licenciamento de Atividades Poluidoras (SLAP), criado em 1977, regulamentou por muitos anos o licenciamento ambiental no Estado. Serviu inclusive de referência nacional, impondo a atividades potencialmente poluidoras a obrigação de obter a licença ambiental em três etapas: Licença Prévia (LP), Licença de Instalação (LI) e Licença de Operação (LO).

Em 2009, o SLAP passou por uma reformulação sendo substituído pelo Sistema de Licenciamento Ambiental (SLAM), onde novos mecanismos foram 
incorporados, consolidando em um único documento vários atos administrativos utilizados na gestão ambiental pública no ERJ, (VALINHAS, 2010). Além disso, foram instituídos critérios para determinar o porte e potencial poluidor dos empreendimentos e atividades de forma a definir quais deles podem, ou não, estar sujeitos ao processo de licenciamento.

Ocorre que o processo de licenciamento ambiental no Brasil apresenta características intrínsecas de sua complexidade. Grande parte dos problemas ocorre quando o empreendedor não consegue atender as exigências mais complexas dos procedimentos do licenciamento com obrigatoriedade de Estudo de Impacto Ambiental (EIA) e Relatório de Impacto Ambiental (Rima). $\mathrm{Na}$ outra perspectiva, o órgão ambiental também deixa transparecer suas fragilidades que vão desde a falta de planejamento interno, morosidade na emissão dos Termos de Referência (TR) até falta de profissionais e de um sistema adequado para resolução dos conflitos (SAITO, 2010).

Faria (2011) lista outros problemas que acarretam na morosidade do processo de licenciamento no Brasil, a saber:

- as deficiências nos processos de comunicação com a sociedade;

- as falhas do modelo de realização de audiências públicas;

- os conflitos políticos internos aos órgãos do setor ambiental;

- a baixa capacitação técnica para analisar, com a requerida qualidade, as informações prestadas nos relatórios preparados pelos empreendedores requerentes de licenças;

- o aumento da influência de argumentos subjetivos e ideológicos;

- a judicialização do processo decisório, motivada, principalmente, pelas ações do Ministério Público e pela fragilidade legal das resoluções do Conama que embasam a tomada de decisão no setor, abrindo espaço para contestações judiciais; e

- a exigência e imposição política de avaliação rápida de projetos prioritários.

Existe na literatura atual inúmeras informações convergentes sobre a problemática do processo de licenciamento ambiental, onde indicam que 0 órgão licenciador é o principal responsável pela demora da análise dos estudos 
e pela emissão das licenças ambientais. Entretanto, nenhuma que abordasse a percepção contrária.

Dessa forma, esse trabalho apresenta um estudo mais detalhado sobre essa problemática a partir do próprio procedimento de licenciamento realizado por um órgão licenciador, nesse caso, o Inea.

\section{MATERIAL E MÉTODOS}

Esse estudo tem caráter primordialmente qualitativo baseado em estudos sobre o licenciamento ambiental e seus instrumentos. O levantamento de dados primários não foi realizado por meio de entrevistas ao público alvo, pois pretendeu-se isentar os resultados de opiniões pessoais. Por isso, o objeto de estudo foram os Processos Administrativos (PA) de requerimento de licença ambiental, documentos legais e guardam todo o histórico de licenciamento de um empreendimento ou atividade.

Parte do resultado foi apresentado por meio de representações como gráficos de colunas, de pizza e linha do tempo, utilizando o software Excel, possibilitando uma leitura mais didática. Ademais, entende-se que essa complementaridade de métodos permite uma compreensão mais ampla sobre os fatos apresentados.

Ademais, buscou-se, também, por meio de pesquisa bibliográfica, um método capaz de subsidiar a análise documental compatível com o volume de dados primários disponíveis. Com isso, selecionou-se o método por amostragem não probabilístico que é uma técnica tradicional que independe de princípios científicos, mas de arbítrio. A seleção, amplitude e avaliação da amostra são baseadas no critério do próprio pesquisador. Sendo assim, considerando o princípio da disponibilidade e da informação, a temporariedade de análise dos processos ocorreu entre os anos de 2012 e 2013.

Diante disso, a seleção das amostras documentais seguiu as fases sugeridas por Calado e Ferreira (2004), onde: identifica-se a localização dos documentos; realiza a seleção dos documentos, considerando os critérios de publicidade e etapa do processo de Avaliação de Impacto Ambiental (AIA); realiza a análise do conteúdo; com posterior apresentação dos resultados.

De modo geral, foram criados critérios para escolha dos PA para análise, onde: Critério 1 - PA localizados dentro do setor de análise do EIA/Rima; 
Critério 2 - PA organizado e de fácil acesso; Critério 3- PA que já passaram no mínimo pela formação de grupo de trabalho e entrega da Instrução Técnica/ Termo de Referência; Critério 4 - Tipologia do empreendimento especificadas no art. 1으, da Lei Estadual no 1.356/ 88; e Critério 5 - PA mais antigo (ano) em tramitação (prioritariamente).

Por fim, foi utilizado também um questionário no sentido de servir de roteiro, orientando o desenvolvimento do trabalho e evidenciar os dados provenientes da pesquisa.

\section{RESULTADOS E DISCUSSÃO}

Baseado no arcabouço legal existente, foi possível realizar uma simulação da tramitação do requerimento de LP de um empreendimento enquadrado como alto potencial poluidor, protocolado no dia 02 de janeiro de 2014, primeiro dia útil do ano.

Diante da simulação, pode-se afirmar que o tempo médio de tramitação de um PA até a emissão da LP ocorrerá em um ano e três meses (15 meses), considerando os dias úteis e possíveis feriados. Ressalta-se também que esse tempo não é uma regra, visto que foi utilizado, para essa simulação, o cenário mais conservador, ou seja, o tempo total previsto para cada etapa. Ademais, o prazo pode ser suspenso caso haja necessidade de complementações dos estudos ou esclarecimentos.

Dessa forma, podemos afirmar que os prazos gerais das principais etapas do processo de licenciamento no estado do Rio de Janeiro, desde a abertura do processo, ocorrem conforme o Quadro 1. 


\begin{tabular}{|c|c|c|}
\hline & Ação & Prazo \\
\hline 1 & Abertura do processo & 1 dia \\
\hline 2 & Criação do GT & 5 dias * \\
\hline 3 & $\begin{array}{l}\text { Comunicação ao servidor sobre sua nomeação ao GT e envio de } \\
\text { documentos sobre o PA }\end{array}$ & 3 dias a 6 dias $^{\star}$ \\
\hline 4 & Apresentação do projeto ao GT pelo empreendedor & 10 dias \\
\hline 5 & Realização da vistoria & 14 dias* $^{*}$ \\
\hline 6 & Elaboraçăo da IT & 21 dias* $^{*}$ \\
\hline 7 & IT no site para críticas e sugestões & 10 dias* $^{*}$ \\
\hline 8 & $\begin{array}{l}\text { Período de elaboração e entrega do EIA/Rima pelo } \\
\text { empreendedor }\end{array}$ & 180 dias \\
\hline 9 & $\begin{array}{l}\text { Checagem do EIA para verificação do atendimento dos itens } \\
\text { exigidos na IT (CheckList) }\end{array}$ & 5 dias \\
\hline 10 & Análise técnica do EIA/Rima pelo Inea & 120 dias \\
\hline 11 & Análise jurídica dos atos do Inea sobre o PA & 7 dias $^{*}$ \\
\hline 12 & Submissão do PA à Ceca & 5 dias $^{*}$ \\
\hline
\end{tabular}

"Năo existe um ato normativo especifico para o prazo informado.

Fonte: Elaboração própria baseado nas resoluções Conama e normativas do Inea sobre o licenciamento ambiental.

Esse trabalho considerou o prazo de 15 meses como o Tempo Referência (TRef) para a apresentação dos resultados da análise documental dos processos analisados em 2012 e 2013. Ou seja, o TRef de 15 meses será o tempo máximo, ideal, que um PA deverá tramitar dentro do órgão licenciador até o empreendedor receber a LP. Caso esse tempo seja ultrapassado entende-se que ocorreram eventos indesejáveis no processo de licenciamento.

De acordo com a quantidade das tipologias identificadas para cada ano, esse trabalho deveria analisar 22 PA. Porém, ao executar a metodologia de seleção dos processos, 4 (quatro) PA não se enquadraram nos 5 (cinco) critérios de recolha documental. Por isso, foram analisados 18 processos de requerimento de LP, sendo 10, em 2012, e 8, em 2013.

Temporalidade dos processos sujeitos a EIA/ Rima analisados em 2012 e 2013 pelo setor de análise de estudos ambientais do Inea. 


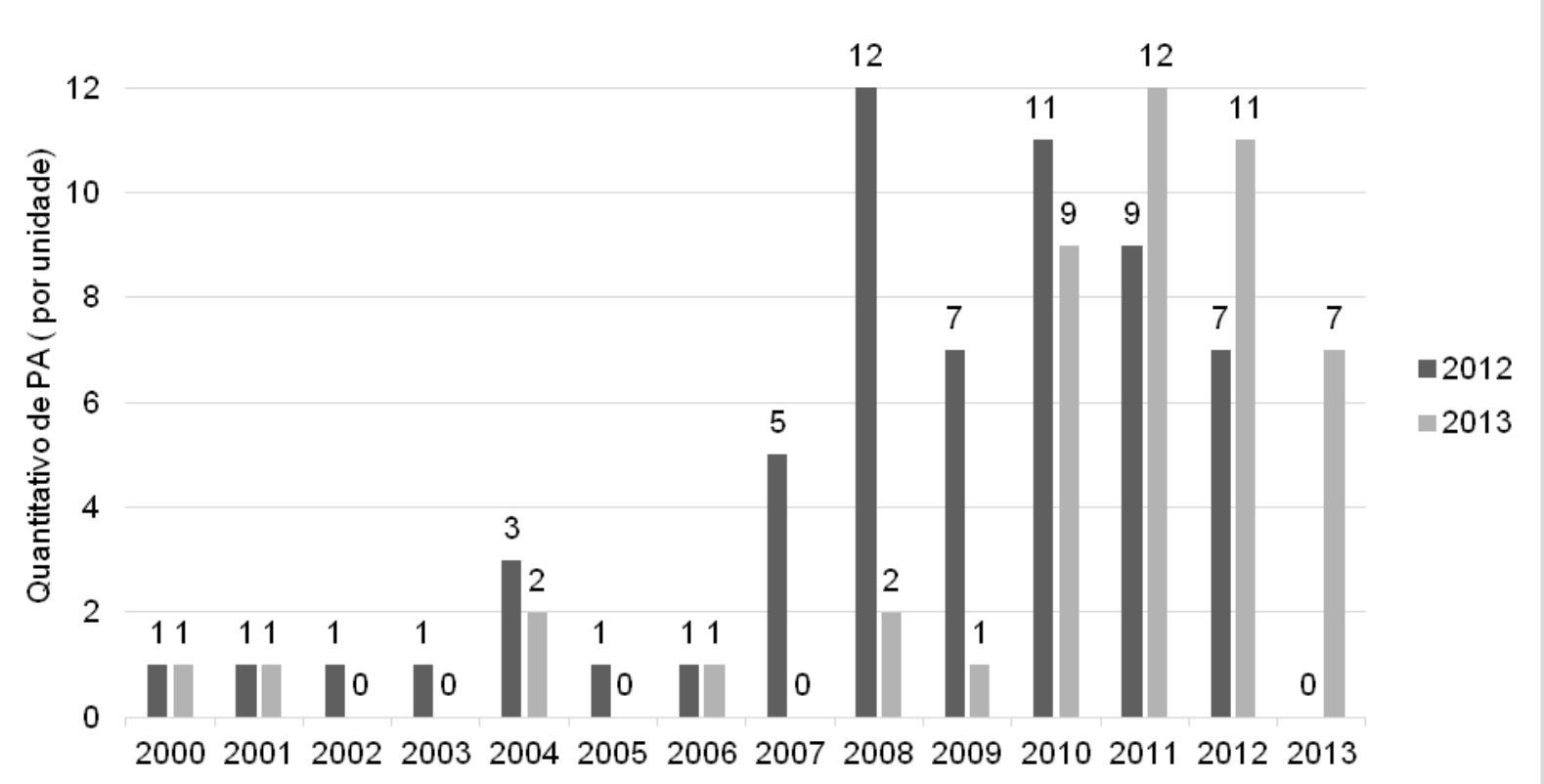

Figura 2: PA analisados em 2012 e 2013 pelo setor de análise de estudos ambientais, por ano de abertura do processo.

A Figura 2 evidencia que em 2012 e 2013 tramitaram no setor de análise de EIA/Rima do Inea processos protocolados há mais de 7 anos e que ainda não foram deliberados quanto à emissão da LP. Além disso, há uma concentração processual a partir de 2007, ano de criação do Instituto. Este maior volume de processos pode ter sido causado pela reestruturação organizacional devido à junção dos três órgãos (Feema, IEF e Serla).

Verificando isoladamente essa informação, pode-se remeter a uma conclusão que a mudança institucional pode ser a causa na demora na análise dos processos de licenciamento ambiental. Entretanto, cabe analisar intrinsicamente as etapas da AIA dos processos de forma a entender esse cenário. Com isso, tem-se os seguintes resultados.

\section{Criação de Grupo Técnico (GT) para análise dos estudos ambientais}




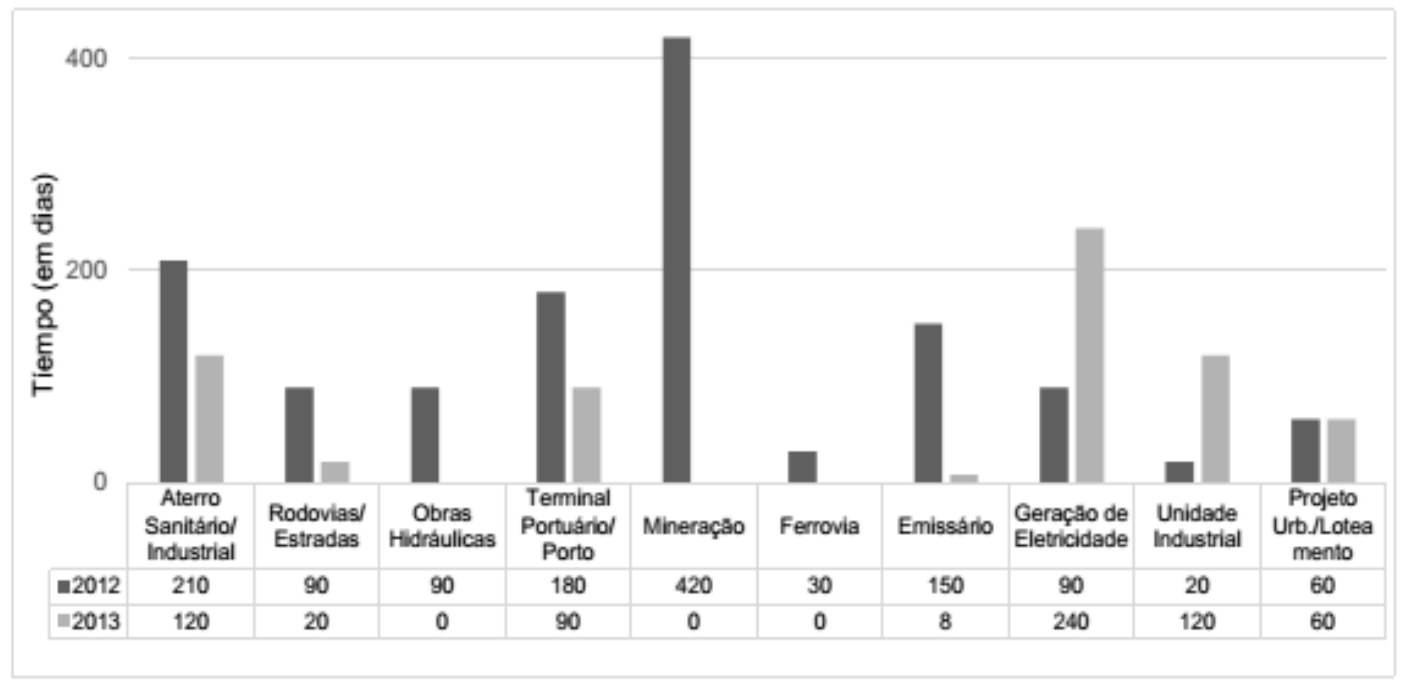

Figura 3: Tempo de criação, em dias, do grupo técnico dos processos analisados em 2012 e 2013, baseado na análise amostral dos PA.

Conforme observado no item referente ao tempo de tramitação do processo de licenciamento sujeito a EIA/ Rima no Inea, a criação do GT deveria ocorrer em até 5 (cinco) dias. Porém, conforme verificado na Figura 3, essa não é a realidade de todos os processos analisados. A única proximidade ao tempo desejado está o processo do emissário, em 2013, que ocorreu em apenas 8 (oito) dias. Porém, o tempo médio de criação do GT dos processos analisados ocorreu em 121 dias. Ou seja, quatro meses.

Nota-se que, no ano 2013, conforme a Figura 3, foram atribuídos valores 0 (zero) nos processos referentes às Obras hidráulicas e Mineração. Isso ocorre porque, em 2012, o GT já havia sido criado, sendo que o tempo para a sua formação ocorreu em 90 e 420 dias, respectivamente. O que demonstra que a tramitação desses processos ocorreu em diferentes estágios nos anos anteriores e, em 2013, tais PA se encontravam em outra etapa do licenciamento. Já a atribuição 0 (zero) no processo de Ferrovia se deve a inexistência dessa tipologia para análise em 2013.

Verifica-se também que, em 2013, houve uma redução do tempo de criação dos vários GT em relação ao ano anterior e, mesmo assim, essa redução ocorreu muito abaixo do esperado. Analisando com mais detalhe os processos recolhidos, ficou evidente que existiram diversos fatores, principalmente em 2012, que protelaram a criação dos grupos técnicos. A Figura 4 evidencia quais foram esses fatores. 


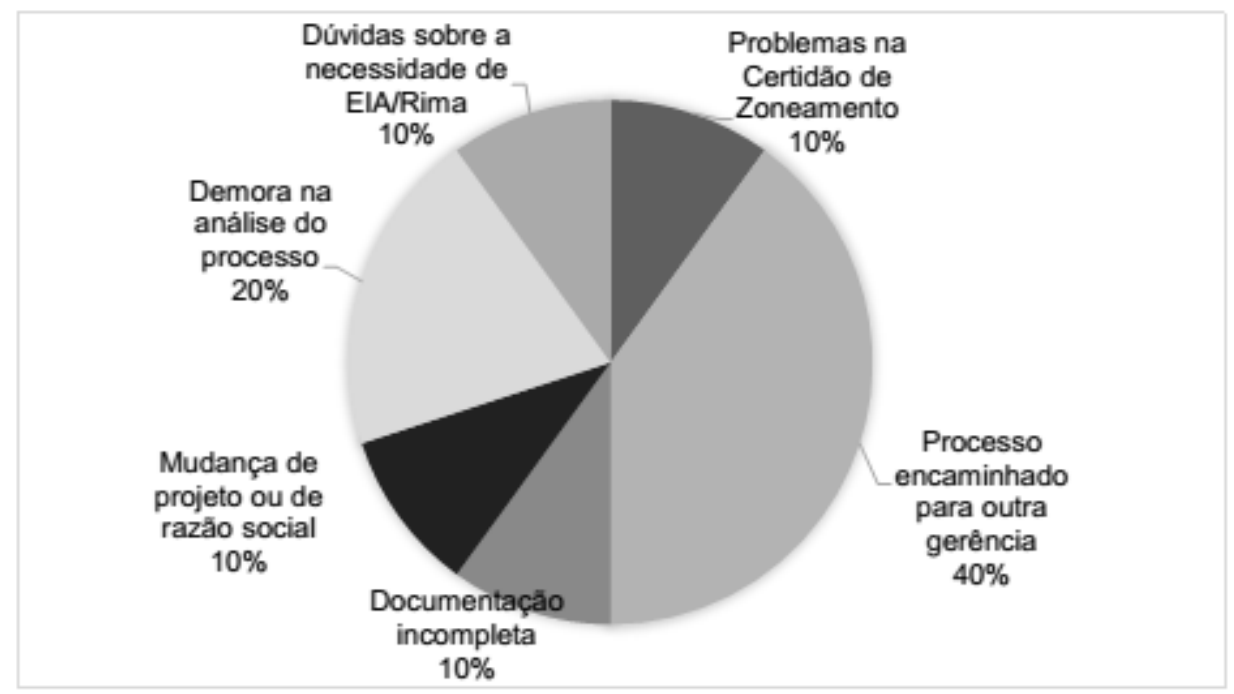

Figura 4: Fatores que interferiram na criação do grupo de trabalho, baseado na análise amostral dos PA.

Conforme observado na Figura 4, existiram dois fatores de maior representatividade sobre o atraso para criação desses grupos. O primeiro fator refere-se à destinação dos processos para outras gerências e o segundo, à demora na análise documental para posterior solicitação de criação do GT.

A destinação dos PA para outras gerências ocorreu devido a um descuido dos servidos administrativos responsáveis pela gestão documental. De outra forma, as gerências que receberam equivocadamente esses processos não tiveram agilidade de comunicar aos responsáveis sobre 0 ocorrido.

Uma hipótese aceitável para tal encaminhamento seria se essas gerências possuíssem quadro pessoal e ações estratégicas voltadas para a tipologia dos empreendimentos, onde por lá a AIA seria melhor coordenada. Porém, não foi o caso dos processos analisados. Essa evidência foi constatada por meio de despachos nos processos, indicando equívocos na entrega desses documentos.

A demora na análise documental ocorreu por excesso de demandas sobre os servidores responsáveis pela análise dos processos. Essa constatação foi verificada por meio de despachos, atas de reuniões e respostas 
às solicitações de informações pelo empreendedor a respeito do andamento do processo.

Constatou-se também que a paralização temporal da análise dos processos ocorreu devido à ausência de documentos importantes, como certidão de zoneamento e contrato social, que são documentos fundamentais para garantir a segurança legal do ato. Porém, entende-se que cabe à central de atendimento ao público do Instituto a verificação de toda a documentação mínima necessária para a abertura do processo de licenciamento requerido. Dessa forma, o principal responsável pelo entrave nessa fase ocorreu por parte do Inea.

\section{Elaboração e entrega da Instrução Técnica (IT)/ Termo de Referência}

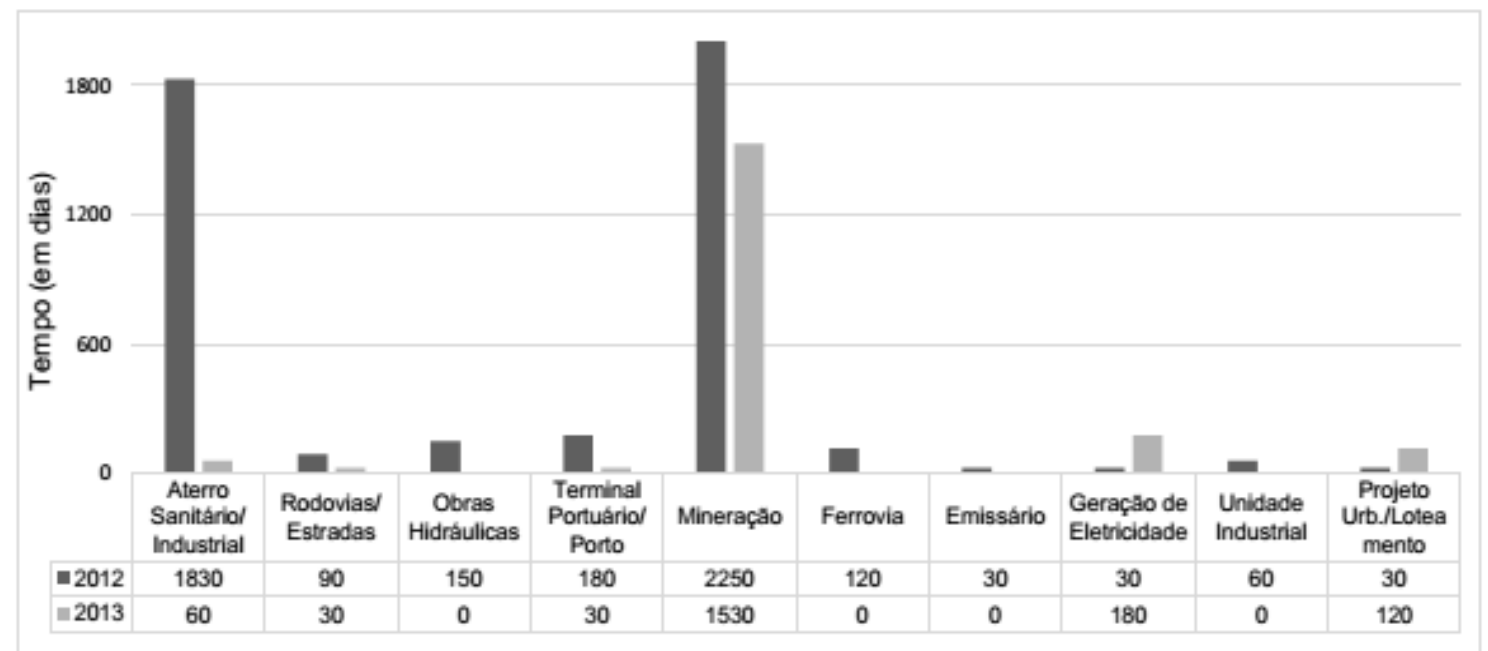

Figura 5: Tempo, em dias, de elaboração e entrega da instrução técnica ao empreendedor, baseado na análise amostral dos PA.

O tempo ideal de elaboração e entrega da IT ao empreendedor deveria ocorrer em 35 dias, após a criação do GT. Porém, conforme a Figura 5, apenas os processos referentes à rodovia, terminal portuário, emissário, geração de eletricidade e de projeto urbanístico/ loteamento, enquadram-se nessa situação.

Após análise documental desses processos, pôde-se perceber que três estavam enquadrados como empreendimentos de utilidade pública. Ou seja, eram empreendimentos de relevante interesse social. Logo, de prioridade para 
o governo. Os demais, provavelmente, foram considerados de baixa complexidade, o que acarretou na agilidade na elaboração e entrega da IT.

Além disso, nenhum dos processos apresentou problemas técnicos ou legais de forma a impedir a entrega da instrução no prazo. Porém, os demais tiveram diversos fatores, Figura 6, que protelaram a ação.

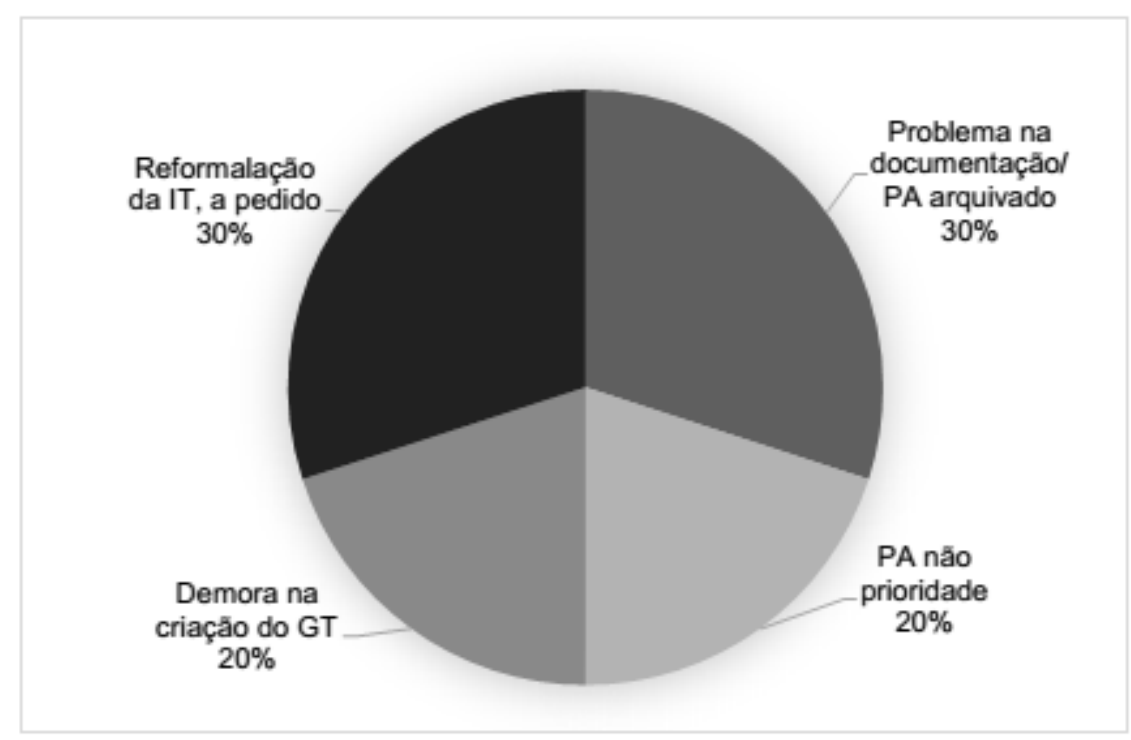

Figura 6: Fatores que interferiram na entrega da instrução técnica ao empreendedor, baseado na análise amostral dos PA.

Conforme observado, existiram diversos fatores que impossibilitaram a elaboração e entrega da IT ao empreendedor.

Os problemas relacionados à documentação ou ao arquivamento dos processos, ocorreram devido à reanálise documental feita pelos GT, com objetivo de prospectar possíveis problemas quanto, por exemplo, à ausência ou validade da certidão de zoneamento apresentada, ou verificação de possíveis divergências nas informações apresentadas pelo empreendedor quando na abertura do processo.

$\mathrm{Na}$ análise documental, constatou-se que as reanálises ocorreram devido às constantes modificações dos projetos, pelos empreendedores, e pela apresentação de certidões de zoneamento que não atendem ao seu objetivo. Ademais, muitos projetos apresentados, por estarem em sua concepção inicial, 
foram revistos pelos empreendedores que, de forma estratégica, solicitaram arquivamento temporário de seus processos.

Quanto à reformulação da IT, a pedido do empreendedor, constatou-se que ao modificar a estratégica empresarial, o empreendedor busca reorganizar seu projeto de forma a adequá-lo às suas novas demandas. Ocorre que, por muitas vezes, a IT já estava pronta ou em fase de finalização, forçando o GT a revisá-la, acarretando em mais tempo para assimilar o que o empreendedor desejava.

A demora na criação dos GT, segundo a análise documental, ocorreu porque que houve a criação de novos grupos para acompanhar os processos, visto que os grupos anteriores foram desfeitos por serem antigos demais ou com baixa diversidade técnica.

Já a questão de prioridade do processo ocorreu, pois as quantidades dos servidores foram consideradas insuficientes frente ao volume de processos de EIA/Rima protocolados para análise. Dessa forma, o órgão viu-se obrigado a priorizar os processos considerados estratégicos, ou seja, os de utilidade pública, para análise. Desse modo, o principal responsável pelo entrave nessa fase ocorreu por parte do empreendedor.

\section{Entrega do EIA/Rima}

O tempo máximo legal de entrega do EIA/Rima pelo empreendedor ao órgão licenciador é de até seis meses (180 dias). Porém, conforme evidencia a Figura 7, apenas 7 (sete) dos 18 processos analisados entregaram os estudos no prazo, 6 (seis) entregaram posteriormente e 3 (três) não foram entregues. 


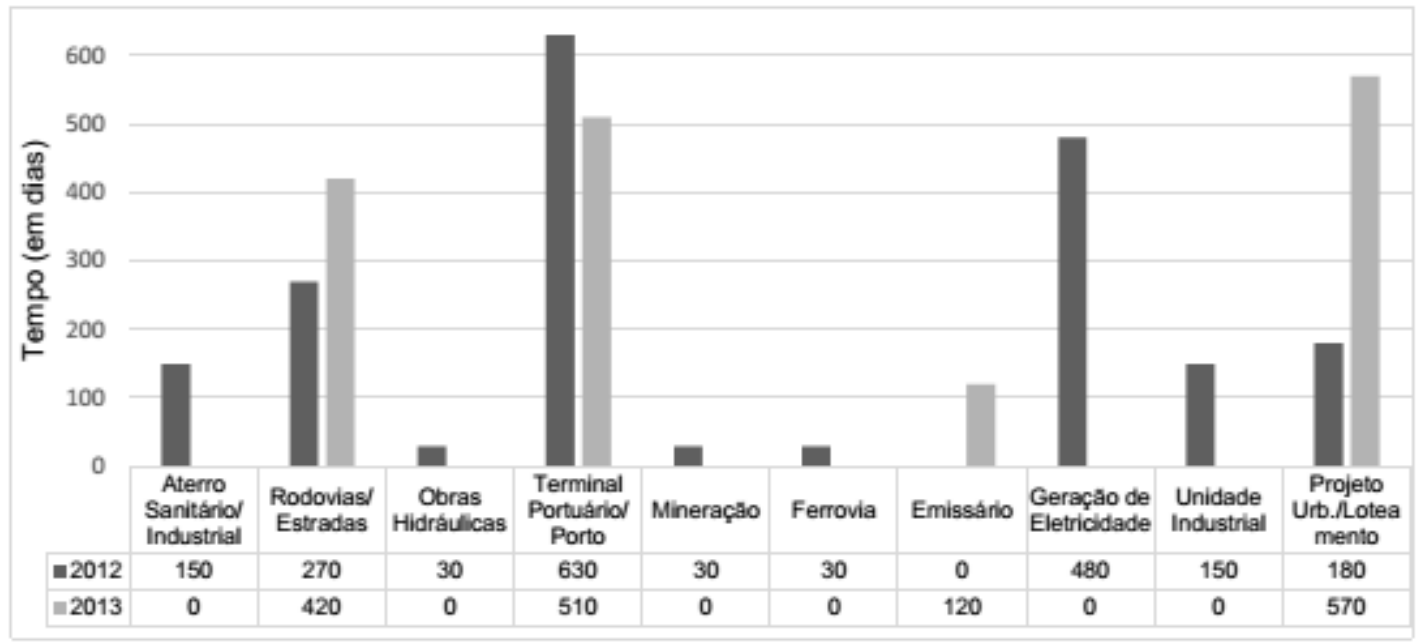

Figura 7: Tempo, em dias, de entrega dos EIA/ Rima após o recebimento da instrução técnica, baseado na análise amostral dos PA.

Nota-se que os empreendimentos alocados na tipologia de obra hidráulica e mineração apresentaram o EIA/Rima em 2012, sendo que em 2013 estão em outro estágio do processo de licenciamento. Ademais, o processo de Ferrovia não foi contemplado na recolha documental em 2013 por não constar no banco de dados do setor que analisa os EIA/Rima do Inea.

Além disso, chama-se atenção que, em 2012, os processos de Obra hidráulica, Mineração e Ferrovia, levaram cerca de 30 dias para entregarem o EIA/Rima. Isso não quer dizer que os empreendedores levaram somente esses dias para elaborar seus estudos. Na verdade, esses processos tiveram vários problemas desde a abertura do PA, acarretando em constantes reuniões técnicas e revisão de estudos ambientais antes de oficializar os atos como entrega da IT e do EIA, para posterior aceite e análise.

Os demais processos apresentam particularidades, conforme a Figura 24, que impediram a entrega dos estudos no prazo. 


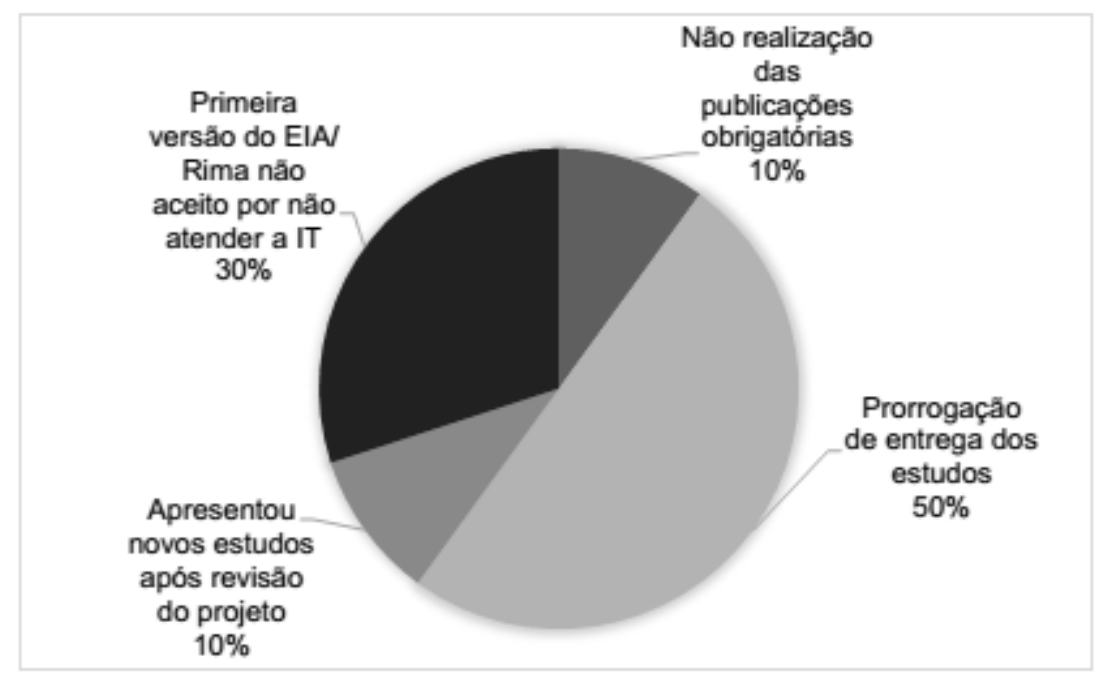

Figura 8: Fatores que interferiram na entrega do EIA/Rima, baseado na análise amostral dos PA.

Segundo análise documental, o maior problema enfrentado nos processos está na prorrogação de entrega dos estudos por parte do empreendedor, conforme evidencia a Figura 8.

A complexidade de estudos ambientais como dispersão atmosférica, hidrodinâmica costeira e diagnóstico de fauna, são os principais motivos que levaram o empreendedor a solicitar a prorrogação de entrega do EIA/Rima. Esses estudos demandam maior tempo de coleta de dados, visto a falta de informações secundárias, como por exemplo, da sazonalidade da região.

Entende-se, porém, que estudos mais detalhados, como da dispersão atmosférica, são necessários para que se tenha uma previsão mais exata dos impactos que os empreendimentos podem causar no meio ambiente. Sua ausência pode fragilizar os objetivos da AIA. Portanto, são necessários.

Outro fator importante que retardou no tempo de entrega do EIA/Rima para análise é a reapresentação dos estudos após o não aceite por não atendimento aos itens obrigatórios da IT. Dessa forma, o responsável pelo entrave nessa fase ocorreu por parte do empreendedor. 


\section{Aceite do EIA/Rima}

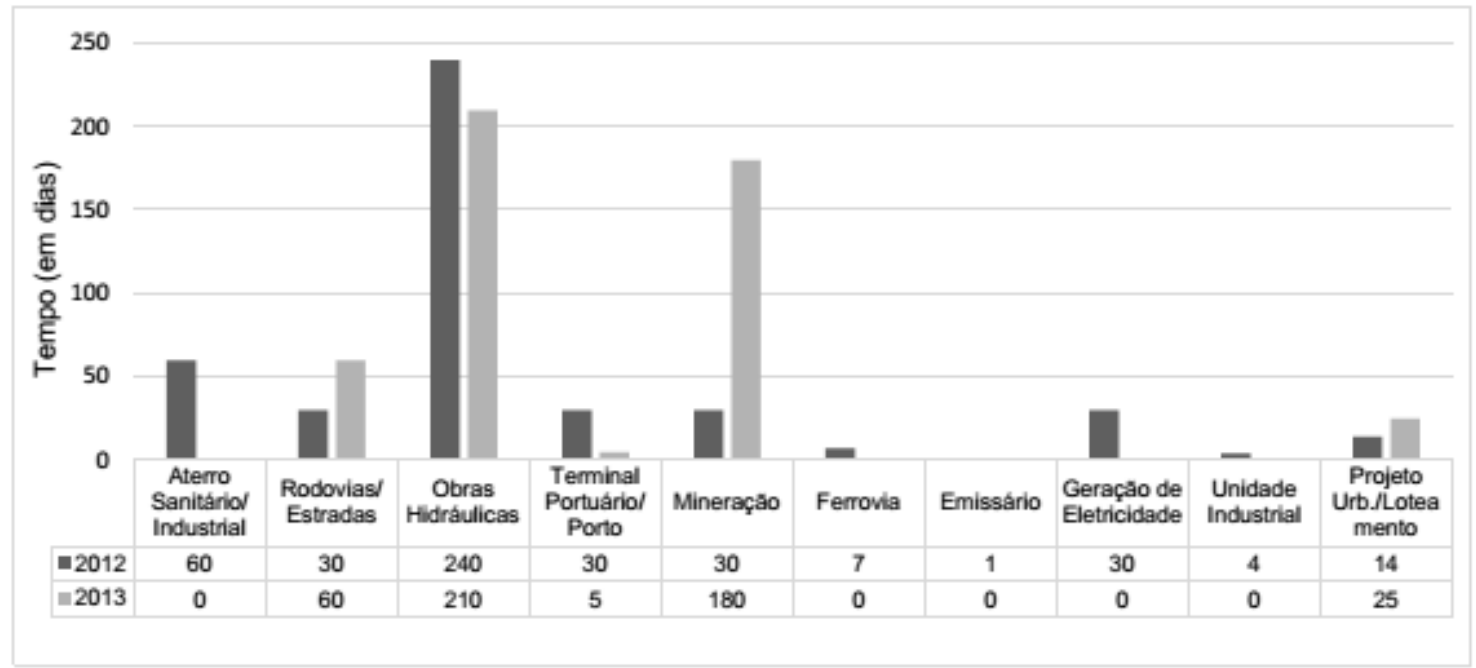

Figura 9: Tempo, em dias, de aceite do EIA/Rima, após protocolado, baseado na análise amostral dos PA

De acordo com a normativa do Inea, o tempo para aceite dos estudos não deverá ultrapassar 5 (cinco) dias. Porém, de acordo com a Figura 9, o tempo de realização do checklist de itemização da IT junto ao EIA foi superior em 11 (onze) processos, sendo que apenas 3 (três) foram realizados dentro do prazo.

Conforme observado, a obra hidráulica passou duas vezes na fase de aceite do EIA/Rima. Tal fato ocorreu porque o GT identificou que os estudos apresentados foram insuficientes para verificar a viabilidade de implantação do empreendimento. Dessa forma, para não perder o processo, o empreendedor se comprometeu em refazer os estudos de forma mais detalhada. $O$ que acarretou na submissão dos estudos novamente, sem que tenha que retroagir as fases anteriores. A Figura 10 apresenta os principais fatores que interferiram no tempo de aceite do EIA/Rima dos PA analisados. 


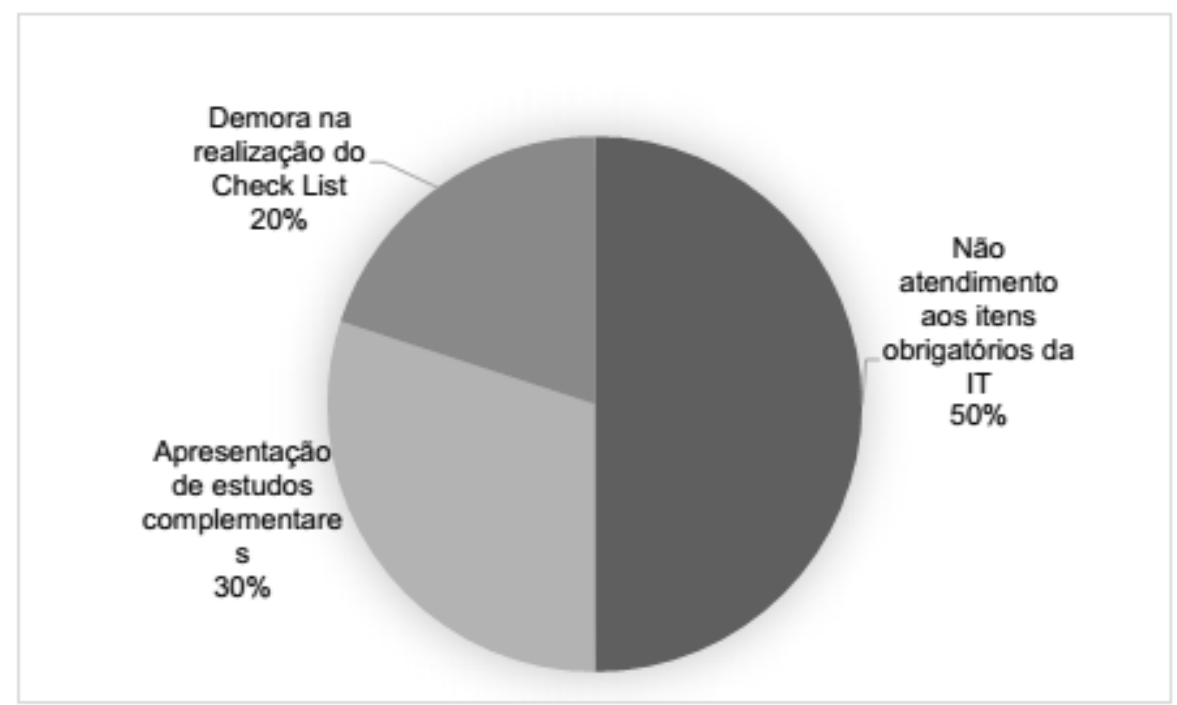

Figura 10: Fatores que interferiram no não aceite do EIA/Rima para análise, baseado na análise amostral dos PA.

Observa-se que metade dos estudos protocolados não atenderam integralmente o que determinada a IT. Também, não apresentaram informações capazes de subsidiar um parecer conclusivo, motivando, assim, o GT a solicitar estudos complementares.

Ao analisar os PA, pode-se observar que houve descuidos de finalização na maioria dos estudos, que vão desde a ausência de itens considerados básicos, como apresentar o mínimo exigido de alternativas locacionais, plantas dos projetos e até os mais complexos, como é o caso de estudos sobre a qualidade do ar e de tráfego.

Cabe ressaltar que o Inea utiliza seu portal eletrônico como espaço democrático de manifestação popular sobre seus atos administrativos, de forma que qualquer cidadão pode ter acesso às minutas das IT e enviar, por email, suas críticas e sugestões. No entanto, muitas vezes, o empreendedor esquece-se desse espaço e, ao receber a respectiva IT, manifesta-se contrário, requerendo alterações ou até mesmo a exclusão dos itens solicitados, acarretando num alongamento temporal do processo. Dessa forma, considerando os aspectos apresentados, o principal responsável pelo entrave nessa fase ocorreu por parte do empreendedor. 


\section{Análise do EIA/Rima}

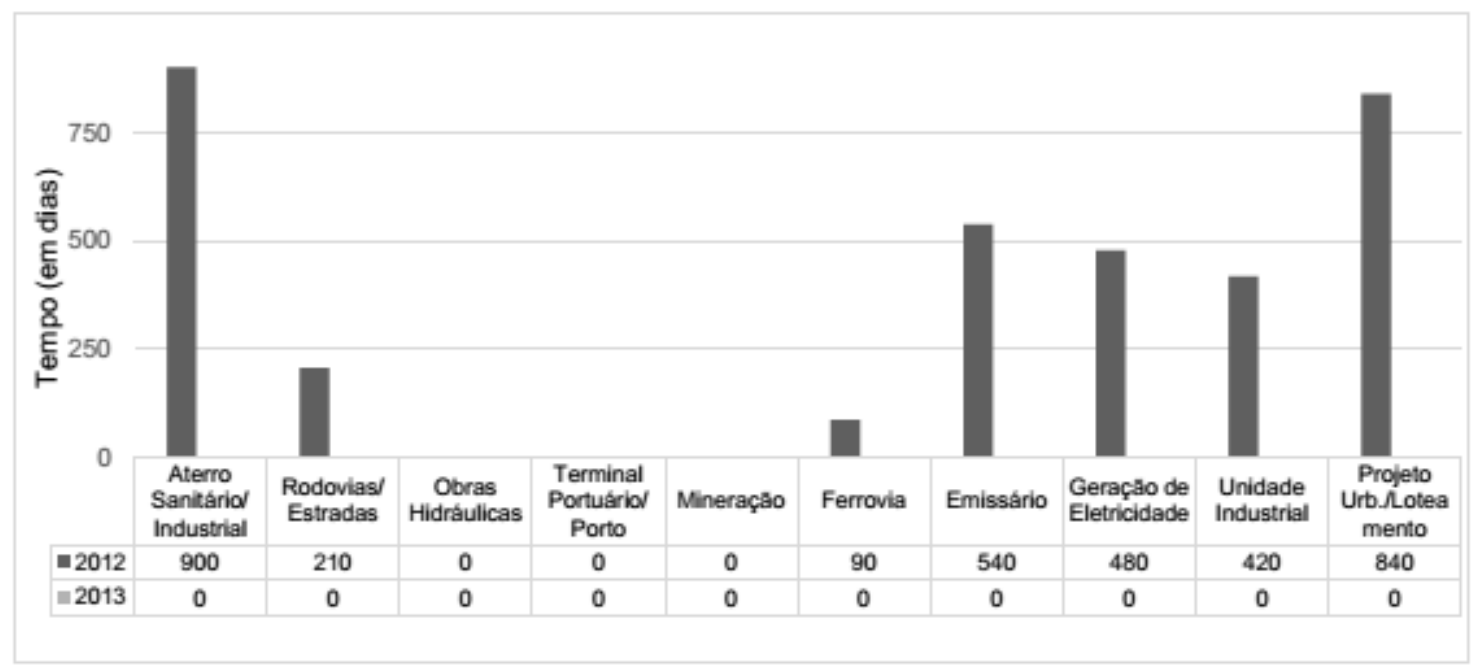

Figura 11: Tempo, em dias, de análise do EIA/Rima, baseado na análise amostral dos PA

Observa-se que dos 14 processos aceitos para análise, Figura 10, o GT conseguiu concluir apenas o processo da Ferrovia, dentro do prazo de 120 dias, Figura 11. Além disso, outros 6 (seis) estudos foram analisados com elaboração de parecer. Porém, muito além do tempo estabelecido. Nos demais, as análises não foram concluídas. Os principais motivos de demora na análise estão evidentes na Figura 12.

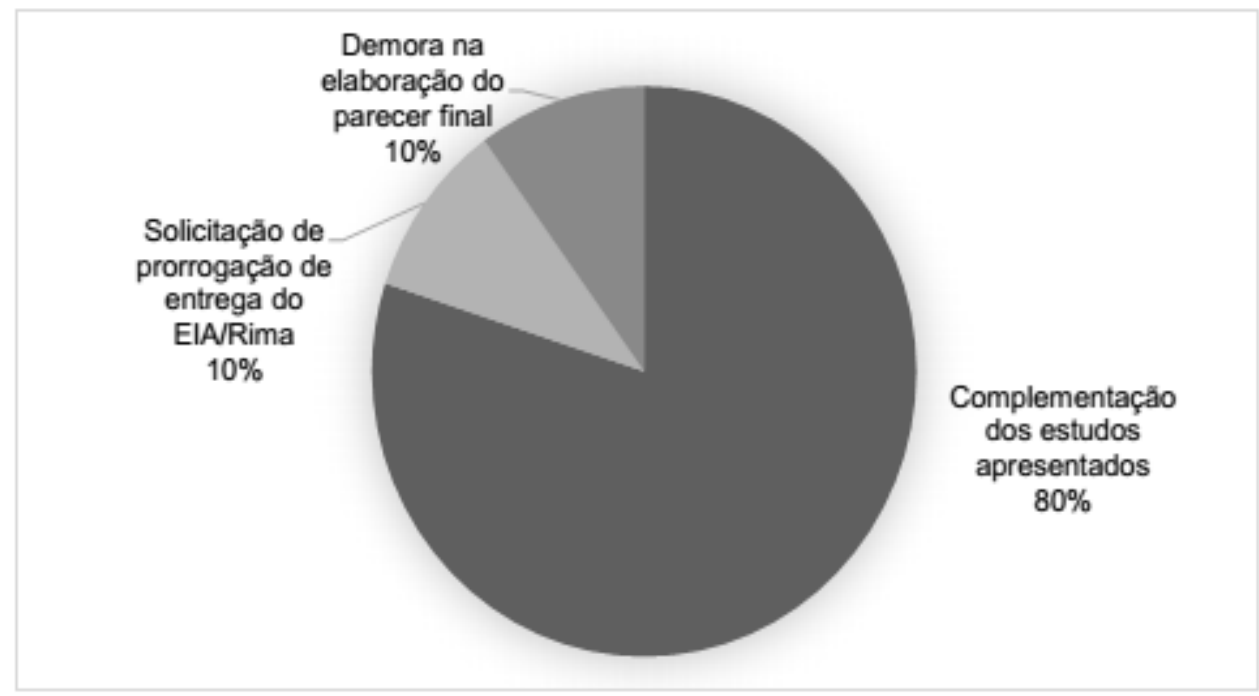

Figura 12: Fatores que interferiram na conclusão do Parecer Técnico Final, baseado na análise amostral dos PA

Após consultar atas de reuniões e notificações dos PA, constatou-se que as fragilidades dos conteúdos apresentados no EIA/Rima levaram o GT a 
reunir-se constantemente com os empreendedores para que prestassem esclarecimentos sobre seus estudos. Com isso, o tempo de análise do EIA/Rima ficou prejudicado, visto que foram paralisados até o recebimento das complementações, Figura 13.

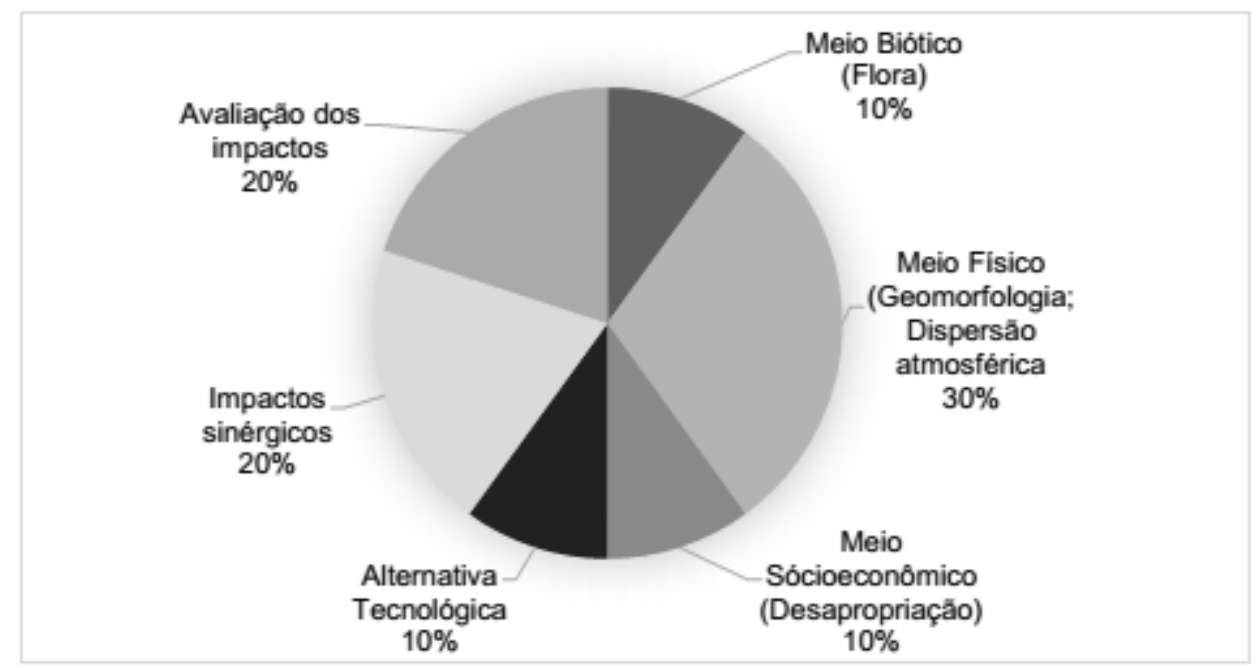

Figura 13: Tipologia dos estudos complementares dos EIA entregues, baseado na análise amostral dos PA

Observa-se na Figura 13 que o maior percentual de complementações ocorreu sobre os estudos considerados mais complexos como, por exemplo, de dispersão atmosférica. Percebe-se que a pressa em submeter o EIA/Rima para análise implicou na finalização inadequada dos estudos, não restando outra opção para o GT a não ser de exigir as complementações pertinentes. Dessa forma, considerando os aspectos apresentados, o principal responsável pelo entrave nessa fase ocorreu por parte do empreendedor.

\section{Participação de outros órgãos e entidades envolvidos no processo de licenciamento}




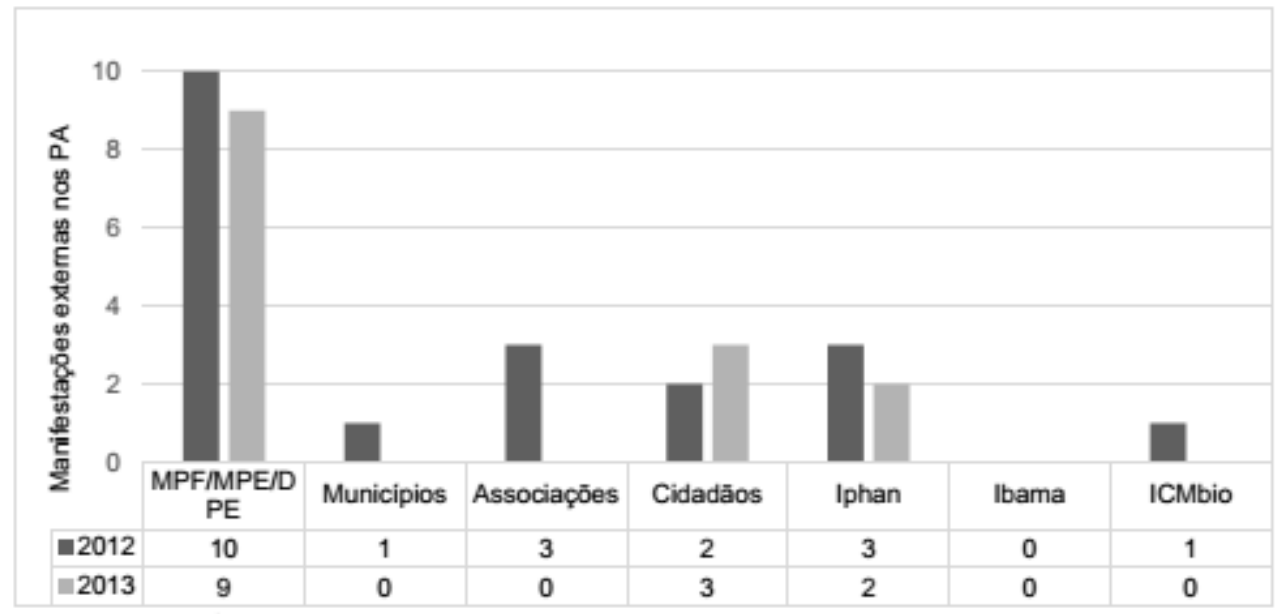

Figura 14: Manifestação de órgãos ou entidades envolvidas no processo de licenciamento, baseado na análise amostral dos PA.

Nota-se, na Figura 14, que as ações dos órgãos fiscalizadores da ordem jurídica, em sua maioria do Ministério Público do Estado (MPE), estão presentes em todos os processos analisados, seja solicitando informações sobre o andamento dos atos administrativos, ou enviando pareceres técnicos jurídicos apontando tratativas de análise do EIA/Rima ao Inea, como é o caso dos pareces jurídicos do Grupo de Apoio Técnico Especializado (Gate) do MPE do ERJ. Dessa forma, a Figura 15 especifica as tratativas do MP sobre os processos.

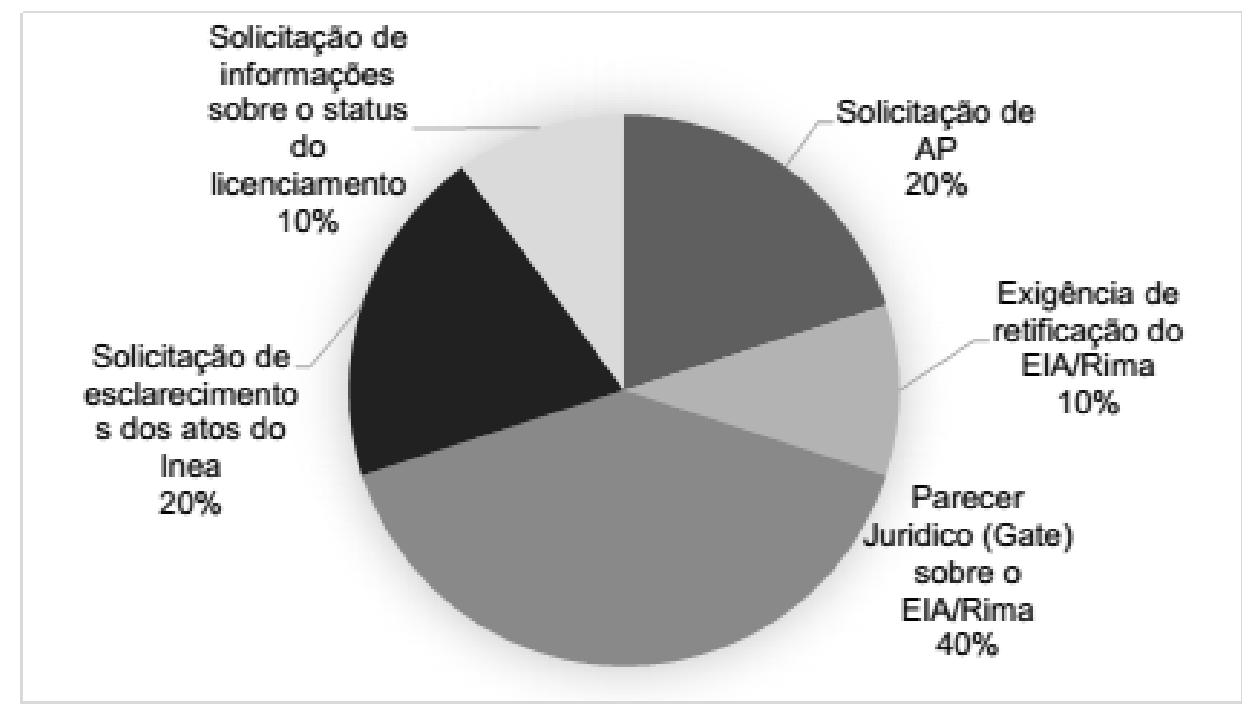

Figura 15: Ações do Ministério Público no curso do licenciamento, baseado na análise amostral dos PA. 
Além de órgãos de ordem jurídica, destacam-se as manifestações de associações civis e de cidadãos comuns de forma a manifestarem preocupação quanto ao conteúdo apresentado na audiência pública, principalmente, no que se refere a desapropriações ou possíveis incômodos à população pela implantação do empreendimento. O Instituto do Patrimônio Histórico e Artístico Nacional (Iphan), por sua vez, atua no processo de licenciamento quando é motivado pelo órgão licenciador a manifestar-se sobre as questões arqueológicas e do patrimônio cultural.

\section{Emissão da Licença Prévia}

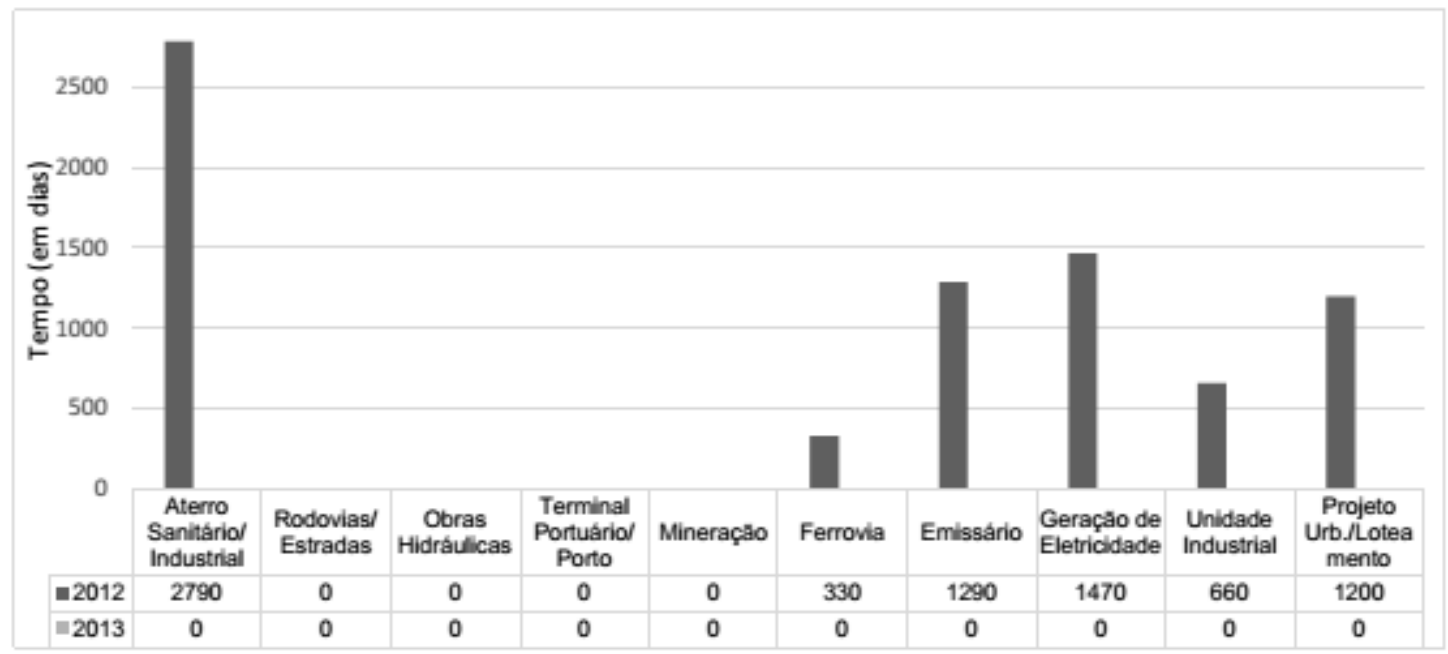

Figura 16: Tempo, em dias, de emissão de Licença Prévia, baseado na análise amostral desde a abertura do PA

De acordo com a simulação elaborada no início desse capítulo, todo o processo de licenciamento deve ocorrer, desde a abertura do processo até a emissão da licença, em 15 meses (450 dias). Contudo, conforme apresentado na Figura 16, apenas o empreendimento correspondente à Ferrovia enquadrase nessa premissa.

Não há dúvidas que os demais processos foram influenciados diretamente pelos fatores apresentados no estudo. Como, por exemplo, necessidade de estudos complementares, ausência de documentos 
obrigatórios do PA, não atendimento aos itens obrigados da IT, reformulação dos projetos, entre outros. Sendo que, em média, os empreendedores aguardaram 38,5 meses (1.290 dias) para receber suas respectivas LP.

Com base nos resultados, observa-se uma série de fatores que influenciam negativamente no processo de licenciamento executado pelo Inea, acarretando na chamada ineficiência da gestão administrativa do órgão ambiental sobre os processos. Entretanto, esse essa trabalho dissertação evidencia que a parte interessada no processo, nesse caso o empreendedor, é o maior responsável por essa situação.

É natural a expectativa do empreendedor em receber a licença ambiental num curto espaço de tempo, de forma a viabilizar a instalação e operação do empreendimento de acordo com seu cronograma. Porém, os estudos ambientais apresentados nem sempre atendem às exigências do órgão licenciador ou não apresentam informações suficientemente capazes de garantir a viabilidade de implantação do empreendimento de forma sustentável.

Dessa forma, os grupos de trabalho, utilizando o princípio da precaução, exigiram, por muitas vezes, que os empreendedores apresentassem mais garantias, por meio dos estudos ambientais, de forma a nortear uma análise mais precisa dos possíveis impactos de seus empreendimentos.

\section{CONCLUSÃO}

Após as análises dos dados, conclui-se que o cenário descrito por Saito (2010) e Faria (2011) não evoluiu positivamente. Entretanto, apesar desse trabalho evidenciar que tanto o órgão licenciador quanto o empreendedor são responsáveis pelas falhas processuais, 0 empreendedor se sobressai por apresentar estudos com baixa qualidade, refletindo diretamente no tempo de tramitação dos processos. 
Se o processo de licenciamento for dividido em 5 (cinco) principais etapas que antecedem a tomada de decisão sobre a viabilidade ambiental de implantação do empreendimento, ou seja, a primeira sendo a criação do GT, a segunda, a elaboração e entrega da IT, a terceira, entrega do EIA/Rima, a quarta, aceite do EIA/Rima, e a quinta, análise do EIA/Rima, o empreendedor, na análise documental amostral realizada, interferiu negativamente no tempo de tramitação em 4 (quatro) dessas etapas, conforme evidencia o Quadro 2.

Quadro 2: Percentagem atribuída aos principais responsáveis pelos problemas ocorridos em cada etapa da AIA, segundo a análise documental amostral

\begin{tabular}{|c|c|c|}
\hline Principais Etapas da AIA & Empreendedor (\%) & Órgão Licenciador (\%) \\
\hline Criação do GT & 30 & 70 \\
\hline Elaboração e entrega da IT & 60 & 40 \\
\hline Entrega do EIA/Rima & 100 & 0 \\
\hline Aceite do EIA/Rima & 80 & 20 \\
\hline Análise do EIA/Rima & 90 & 10 \\
\hline
\end{tabular}

De acordo com os resultados, os empreendedores falham ao apresentar rotineiramente projetos inconsistentes e estudos ambientais frágeis, obrigandoos a complementá-los no curso do processo de licenciamento. De outra forma, o órgão licenciador também enfrenta uma série desafios de modernização dos processos da AIA que contribuem no prolongamento do tempo de emissão da licença requerida.

Os estudos, ao serem analisados pelo órgão licenciador, apresentam ausência de aspectos técnicos que fragiliza o processo de análise e de identificação dos impactos ambientais, o que compromete na tomada de decisão sobre a viabilidade ambiental dos empreendimentos. 
Dessa forma, ao colaborar com os estudos técnico-científicos sobre o processo de licenciamento ambiental e seus entraves no Brasil esse trabalho evidencia, além dos fatores já consolidados na literatura atual, os seguintes fatores:

- Os projetos apresentados não possuem aspectos técnicos suficientemente capazes de subsidiar a tomada de decisão sobre a viabilidade ambiental do empreendimento;

- O empreendedor realiza constantes modificações do projeto no curso do licenciamento;

- O empreendedor não participa ativamente na elaboração da instrução técnica;

- O empreendedor submete os estudos ambientais incompletos para análise;

- O empreendedor desconhece os procedimentos da AIA.

\section{REFERÊNCIAS BIBLIOGRÁFICAS}

CALADO, S.S., \& FERREIRA, S.C.R. (2004). Análise de documentos: método de recolha e análise de dados. Disciplina Metodologia da Investigação I Mestrado em Educação/Universidade de Lisboa. Disponível em:< http://www.educ.fc.ul.pt/docentes/ichagas/mi1/analisedocumentos.pdf>. Acesso em: 20 de set. 2013.

FARIA, I. D. Ambiente e Energia: Crença e Ciência no Licenciamento Ambiental-Parte III: Sobre Alguns dos Problemas que Dificultam 0 Licenciamento Ambiental no Brasil. 2011. Brasília/DF. Disponível em:<http://www12.senado.gov.br/publicacoes/estudos-legislativos/tiposdeestudos/textos-para-discussao/td-99-ambiente-e-energia-crenca-e-ciencianolicenciamento-ambiental.-parte-iii-sobre-alguns-dos-problemas-quedificultam-olicenciamento-ambiental-no-brasil>. Acesso em: 14 fev. 2013.

RIO DE JANEIRO (Estado). Lei o 1.356, de 03 de outubro de 1988. Dispõe sobre os procedimentos vinculados à elaboração, análise e aprovação dos 
Estudos de Impacto Ambiental. Disponível em:<http://www.bvsde.paho.org/bvsacd/cd38/Brasil/L1356.pdf>. Acesso em: 20 fev. 2013.

SAITO, E. R. F. Cenário do licenciamento ambiental - Principais entraves Análise das competências ambientais no sistema federativo brasileiro. 2010. 274f. Dissertação (Mestrado em Direito Urbanístico) - Centro de Ciências Humanas, Pontifícia Universidade Católica de São Paulo, São Paulo, 2010.

VALINHAS, M. M. Licenciamento ambiental e sustentabilidade - Boletim do Observatório Ambiental Alberto Ribeiro Lamego, Campos dos Goytacazes/RJ, v. 4, n. 2, p. 231- 246. jul. / dez. 2010.

Recebido: 04/09/2014

Aprovado: 29/01/2014 